\title{
PROPOSTAS CURRICULARES ALTERNATIVAS: PERSPECTIVAS PARA A EDUCAÇÃO EM ENGENHARIA
}

\author{
Elize Keller-Franco ${ }^{1}$ \\ Cristina Zukowsky-Tavares ${ }^{2}$
}

\begin{abstract}
Resumo: $\mathrm{O}$ presente trabalho de caráter reflexivo teórico-prático tem por objetivo discutir o papel do currículo na construção de novos cenários no ensino de engenharia. Mundialmente vem sendo reconhecida a importância de novas abordagens para atender as demandas colocadas para a profissionalidade dos engenheiros a partir das mudanças na sociedade. No entanto, pouco se tem discutido e pesquisado sobre a dificuldade dessas mudanças ocorrerem no contexto de concepçôes curriculares tradicionais. Esse artigo descreve e analisa duas experiências de inovação curricular voltadas para a busca de novos caminhos na formação em engenharia a partir dos referenciais colocados na atualidade. Trata-se do currículo cooperativo e do currículo por projetos. Os resultados sugerem a viabilidade desses currículos criarem novos cenários no ensino de engenharia ao serem capazes de mobilizar mudanças em um conjunto de elementos considerados relevantes para novas práxis nessa área de formação.
\end{abstract}

Palavras chave: Ensino de Engenharia. Currículo Cooperativo. Currículo por

Projetos.

\begin{abstract}
The present study of theoretical-practical reflexive character has the objective to bring to discussion the role of the curriculum in the construction of the new scenarios in the teaching of engineering. Worldwide it has been recognized the importance of new approaches to answer the demands placed to the professional of the engineering by the changes of the society. However, it is not discussed and researched much about the difficulties of those changes that happened in the context of the traditions curriculum conceptions. This article describes and analyzes two experiences of curriculum innovation focused to search new paths in the engineering formation from references that it was placed in the last years. This is about the cooperative curriculum and the curriculum by projects. The results suggest a viability of these curriculums to create new scenarios in the engineering teaching by being able to mobilize changes in one conjunct of elements considered relevant for new praxis in this formation area.
\end{abstract}

Keywords: Ensino de Engenharia. Currículo Cooperativo. Currículo por

Projetos.

1. Doutora e mestre em Educação e Currículo pela PUC/SP. Docente no Mestrado em Educação e no curso de Pedagogia do Centro Universitário Adventista de São Paulo. E-mail: elizekeller@gmail.com

2. Doutora em Educação e Currículo pela PUC/SP e Pós-doutora em Educação pela Feusp. Coordenadora do curso de Pedagogia e Docente Mestrado Profissional em Promoção da Saúde na Instituição Centro Universitário Adventista de São Paulo - Unasp SP. E-mail: cristina.tavares@unasp.edu.br 


\section{INTRODUÇÃO}

As últimas décadas têm presenciado profundas alteraçôes nas esferas ambiental, profissional, política, econômica e social, desafiando as instituiçôes, e em especial as instituiçôes educacionais, a uma constante análise e revisão das suas concepçôes e processos.

$\mathrm{Na}$ educação específica em engenharia, estão ganhando reconhecimento em âmbito mundial, o esgotamento dos modelos pedagógicos e a necessidade da busca de novas abordagens mais condizentes com os desafios da sociedade contemporânea.

Tem se intensificado na produção acadêmico-científica, nos congressos e eventos, o debate sobre a importância e a urgência de um novo perfil profissional, que alie à formação técnica específica da área uma sólida formação interdisciplinar, habilidades de comunicação e gestão, atitudes para trabalhar em equipe, autonomia para escolher cursos de ação e habilidades para elaborar e conduzir projetos. A compreensão do perfil ampliado dos profissionais da engenharia está presente também nas políticas educacionais expressas no marco legislatório brasileiro ao apontar que "o novo engenheiro deve ser capaz de propor soluçóes que sejam não apenas tecnicamente corretas, ele deve ter a ambição de considerar os problemas em sua totalidade, em sua inserção numa cadeia de causas e efeito" (BRASIL, 2001, p.1).

No entanto, esses direcionamentos têm refletido pouco no cotidiano dos contextos educativos levando-nos a indagar porque apesar de tantos debates temos avançado táo pouco?

O que se observa com frequência, em grande parte dos cursos de engenharia, são organizaçôes curriculares fundamentadas em uma concepção tradicional de ensino e avaliação. Consideramos nesse trabalho a possibilidade de que o paradigma curricular técnico-linear disciplinar, ainda dominante no cenário educacional em geral e nos cursos de engenharia, se mostra inadequado para articular o conjunto de alteraçóes necessárias à inovação na educação superior, colocando como desafio a busca de modelos curriculares construídos sob novas bases, capazes de promover uma visão integrada, complexa, global e emancipatória do conhecimento.

O presente trabalho traz para reflexão duas organizaçōes curriculares alternativas para a educação em engenharia. Uma trata-se de currículo cooperativo e a outra do currículo por projetos. As reflexóes em torno dessas duas modalidades curriculares decorrem dos estudos desenvolvidos no Grupo de Pesquisa Paradigmas Curriculares e Formação de Professores - FORPEC, sediado no Programa de Pós-Graduação em Educação: Currículo da Pontifícia Universidade Católica de São Paulo (Brasil).

Primeiramente vamos apresentar o currículo cooperativo desenvolvido em alguns cursos de engenharia da Escola Politécnica de São Paulo-USP. Esse estudo baseou-se em uma pesquisa documental e entrevista com um de seus mentores. Na sequência vamos apresentar o currículo por projetos com base em um estudo exploratório descritivo que teve como cenário a Universidade 
Federal do Paraná-Setor Litoral. A partir dessas duas pesquisas, abordaremos a questão orientadora desse trabalho: qual o potencial mobilizador dessas abordagens curriculares alternativas para novos cenários e novas perspectivas na educação em engenharia? Que ideias-força para novos cenários na educação em engenharia perpassam essas duas experiências?

\section{A EDUCAÇÃO COOPERATIVA NO CONTEXTO DAS PRÁTICAS CURRICULARES ALTERNATIVAS EM ENGENHARIA}

A implantação do ensino de Engenharia no Brasil remonta ao final do século XIX, época em que o positivismo como movimento filosófico influenciava o pensamento pedagógico no país. A ciência tendo como base o modelo de conhecimento cartesiano e positivista, não tinha a intenção de refletir sobre os seus significados. Restringia-se a calcular, prever, classificar e inventariar dados empíricos. Nesse modelo fundamentavam-se propostas curriculares, estruturadas independentemente da história, da contextualização e dos processos sociais envolvidos.

O estudante da graduação assumia uma função passiva diante dos saberes em desenvolvimento. Dessa forma, a orientação filosófica e curricular predominante nos cursos de engenharia no Brasil foram construídas sob um modelo de racionalidade técnica e instrumental direcionando suas atividades para promover a adaptação do estudante ao sistema produtivo.

Entretanto, nas últimas décadas, novas demandas se colocam para os engenheiros na direção de um perfil profissional mais autônomo, empreendedor, com habilidades de liderança, trabalho em equipe, reflexão e atuação crítica.

Os cursos e currículos para formação dos engenheiros não podem ficar dissociados dos desafios impostos pelo nosso século, o que faz a universidade repensar seus programas e projetos. Um novo ideário pedagógico para o ensino na engenharia impulsiona a ciência a fazer uma reflexáo sobre si mesma, pois os progressos industriais e tecnológicos não podem ser separados da forma como o conhecimento foi constituído. A engenharia passa a ser repensada dentro de uma nova base de formação muito mais questionadora e atualizada. Do saber técnico-instrumental volta-se ao campo do saber emancipatório (LAUDARES; RIBEIRO, 2000).

Essas questôes trazem consequências específicas para o engenheiro em seus currículos de formação:

Conhecimentos na área de informática e de administração são cada vez mais necessários, assim como o saber vinculado à gestão de custos, de tempo e de recursos humanos. Somam-se a esses conhecimentos os aspectos comportamentais e atitudinais, 
especialmente a capacidade de comunicação, de adaptar-se a situaçóes novas que envolvem responsabilidades crescentes, capacidade de crítica e autocrítica, de suportar trabalho sob tensão, capacidade de negociação, de convencimento e de raciocínio analítico. Tais habilidades tornam-se necessárias para integrar uma multiplicidade de aspectos decorrentes de outras áreas de atuação que não meramente a técnica (LAUDARES; RIBEIRO, 2000, p.497).

A formação enciclopédica e racional dos currículos em engenharia é insuficiente para formar um profissional que não seja apenas capacitado a montar projetos e cálculos de natureza técnica, mas que assuma um conjunto de atividades como líder e agente multiplicador de novos processos de trabalho envolvendo questôes técnicas, econômicas e socioadministrativas, e que tenha um olhar voltado não apenas às necessidades locais, mas também globais.

Nesse contexto de mudanças, surge nos cursos de engenharia, a proposta de um novo currículo denominado Cooperativo. Já em desenvolvimento em alguns países, ele surge no Brasil por volta dos anos 1990 como alternativa para trazer respostas às necessidades mais atuais de formação do engenheiro em nossa realidade.

\subsection{O CURRÍCULO COOPERATIVO EMI ENGENHARIA}

Educação Cooperativa é uma proposta que promove a aprendizagem mediante uma cooperação mais intensa entre os estudos teóricos e as práticas supervisionadas, articulando períodos de aulas (módulos acadêmicos) e períodos de estágio (módulos de estágio). O modelo integra ambientes de aprendizagem e de trabalho aliando as diretrizes acadêmicas da formação profissional à dinâmica do mundo do trabalho.

Esse currículo é chamado Cooperativo por integrar empresas conveniadas e instituiçóes de ensino na formação de profissionais habilitados para as rápidas transformações e inovações nos mais diferentes âmbitos dessa área de trabalho.

A experiência com esse currículo, introduzida na Inglaterra no início do século passado no Curso de Engenharia, foi estendida em 1906 à Universidade de Cincinnati, (USA). Em 1957, foi incluída em Waterloo (Canadá), chegando ao Brasil em 1989 na Escola Politécnica da Universidade de São Paulo, passando em 2001 para a Engenharia de materiais da Universidade Federal de Santa Catarina e em 2002 foi introduzida na Universidade Estadual do Amazonas.

A formação de um profissional em engenharia envolve aspectos técnicos e acadêmicos, pessoais e gerenciais. Uma empresa, ao contratar, busca um Engenheiro que, ao sair da faculdade, tenha uma sólida formação acadêmica, com forte identidade e competência profissional que viabilize o seu agir em determinada empresa de maneira proativa. 
Nessa direção, um currículo em Educação Cooperativa, leva a sala de aula universitária para dentro da empresa. Durante o curso, os alunos cumprem uma carga obrigatória de estágios integrados ao currículo acadêmico. O Curso Cooperativo de Engenharia é constituído por 9 módulos acadêmicos (aulas em período integral) e 5 módulos de estágios, alternados entre si. O primeiro ano do curso é igual aos demais cursos de engenharia. A partir do segundo ano, os módulos são quadrimestrais (fevereiro/abril, maio/agosto, setembro/dezembro), alternando-se os módulos acadêmicos e de estágio com uma semana de férias entre eles. O aluno, no módulo de estágio, assume a vaga na empresa, interrompendo as atividades acadêmicas na escola de engenharia. No quadrimestre seguinte, o aluno retorna à universidade, cedendo a vaga para um outro aluno do Curso Cooperativo, e assim sucessivamente. Essa formatação pode assumir variaçôes, sendo que algumas vezes a alternância dos módulos empresa-academia pode ocorrer já no primeiro ano, ou ainda ser introduzida a estrutura quadrimestral somente a partir do terceiro ano.

Durante os estágios, o aluno percorre diversos setores de uma empresa, ele monta o seu próprio plano de carreira e escolhe as empresas nas quais quer estagiar. Assim, o que diferencia um Currículo Cooperativo de outro currículo em engenharia é que o aluno, durante o curso, vivencia a realização de todos os aspectos das tecnologias atuais, mantendo-se atualizado com as necessidades concretas da sua profissão, tornando-se um especialista na integração das diversas áreas envolvidas no ramo, além de, terminada a faculdade, ter no currículo aproximadamente vinte meses de experiência comprovada em carteira de trabalho na área escolhida.

Destaca-se como significativo nessa modalidade curricular que em cinco anos de curso o estudante agrega aproximadamente dois anos de experiência em diferentes ambientes produtivos da engenharia e algumas vezes até um tempo maior. Tal inserção no mundo do trabalho oferece o cenário para o desenvolvimento de um novo perfil profissional:

O estágio coloca-se em posição de destaque, porque proporciona ao aprendiz um desenvolvimento de suas competências profissionais atuando em ambientes próprios de sua futura profissão. Ao mesmo tempo em que integra prática e teoria, o estágio colabora para que o aprendiz viva o ambiente, o cenário, os personagens, os grupos, os companheiros, o ambiente físico, os problemas e as questóes do dia a dia de sua profissão (MASETTO; PACHECO, 2007).

No entendimento de Matai (2001) os estágios motivam os alunos a ir além dos programas acadêmicos previstos nas ementas das disciplinas, eles voltam à universidade com fome de conhecimento face às inúmeras situaçóes e desafios gerados no ambiente profissional. Abre-se assim a possibilidade de articulação do desafiador binômio teoria-prática no ensino em Engenharia podendo-se a partir desse patamar desenvolver mecanismos constantes de atualização do currículo acadêmico a partir das dúvidas e reivindicações atualizadas do mercado de trabalho. 
As alteraçóes propostas nos projetos cooperativos também apresentam um processo avaliativo diferenciado que deve ser contínuo e intencional. $\mathrm{Na}$ avaliação da aprendizagem discente propóe-se um atendimento no sentido de reorientação das aprendizagens na medida em que o professor-orientador ao acompanhar o estudante durante seu estágio em ambiente profissional tem a oportunidade de avaliar também a sua atuação docente em sala de aula podendo rever e alterar o andamento do seu plano de ensino nos módulos teóricos desenvolvidos na universidade. Para compor a nota final do estágio discutem-se os pareceres do professor-orientador, do engenheiro supervisor na empresa e o relatório elaborado pelos alunos.

A avaliação no currículo cooperativo busca um envolvimento efetivo do aluno no seu próprio projeto de aprendizagem em termos de autorregulação e comprometimento com o aprender no ensino superior. $\mathrm{O}$ ambiente profissional é bem adequado para esse processo avaliativo e permite ao estudante identificar possibilidades e limites, conscientizando-se melhor do seu potencial pessoal e profissional com indicadores críticos na construção e reconstrução de sua formação em engenharia.

Em recente estudo no estado de Minas Gerais que abordou um recorte de universidades brasileiras (FURTADO, 2013), foi observado que poucas instituiçôes de ensino possibilitam um relacionamento entre os estudantes de engenharia e empresas de suas áreas de atuaçáo por meio de programas de pesquisa e extensão, estágios, seminários e visitas. Mas, as visitas menos estruturadas em termos de planejamento foram predominantes, apontando para uma frágil interface entre os aspectos teóricos e práticos na formação do engenheiro, fato esse que reforça a importância de uma organização curricular que intensifica o contato organizado, refletido e acompanhado do estudante nos ambientes profissionais em que se dá o exercício da profissão.

\subsection{IDEIAS-FORÇA PARA NOVOS CENÁRIOS NA EDUCAÇÃO EMI ENGENHARIA}

A organização curricular articulando módulos acadêmicos e de estágios valoriza a articulação da teoria e da prática ao longo do curso. A integração da universidade com as empresas favorece uma ressignificação e atualização dos conteúdos que passam a ser mais próximos das necessidades reais dos ambientes profissionais.

Alteração significativa pode ser sentida na organização dos espaços e tempos do currículo. Os espaços de aprendizagem estendem-se para além das salas de aulas mediante os quadrimestres nas empresas. A organização do tempo não fica sujeita a tradicional dicotomia, primeiro a formação na academia e no final do curso, a formação no campo de estágio.

Dignas de atenção também são as alteraçóes construídas no que diz respeito ao papel do professor e do aluno, com valorização das relaçóes de trabalho em equipe e da corresponsabilidade. 
Os alunos são incentivados a mudanças de atitudes por meio de atividades concretas nos estágios e projetos que lhes propóem participação, trabalho, pesquisa, diálogo e debate com outros colegas, com o professor e com profissionais. Quanto ao professor, destaca-se a quebra de paradigma das funçóes da docência ao exigir um novo papel do professor como intelectual pesquisador, crítico, cidadão e planejador de situaçóes de aprendizagens; mediador e incentivador dos alunos em seus processos de aprender; trabalhando em parceria com os alunos, colegas professores e profissionais das empresas; aprendiz ao abrir a perspectiva de rever sua prática a partir das experiências dos alunos nos estágios, integrando efetivamente a teoria à prática.

E, por fim, toda a metodologia de aprendizagem e processo avaliativo foram significativamente alterados. A metodologia privilegiando a participação do aluno, a interação entre eles, o professor, a realidade e os profissionais das empresas, a colaboraçáo na construção do conhecimento e na aprendizagem na prática. A avaliação integrada ao processo, como elemento motivador e incentivador da aprendizagem, com feedbacks contínuos, incentivando os estudantes a uma busca de crescimento contínuo.

O estágio é um elemento de destaque nessa proposta ao favorecer que durante o curso o aluno já possa consolidar sua identidade profissional. A ressignificação do estágio representa um grande avanço frente ao ensino tradicional e solitário da sala de aula principalmente se trouxermos para o debate que a relação entre a teoria e a prática no ensino superior continuam como um dos maiores desafios da universidade na formaçáo de seus profissionais na contemporaneidade.

Refletindo nas características e princípios norteadores de um paradigma curricular inovador no Ensino Superior assinalados por Masetto (2005) encontramos elementos nessa proposta que alteram a metodologia, relação teoria/prática, o perfil do estudante, a dimensão espaço/tempo e a avaliação da aprendizagem.

Nota-se que tal currículo produziu alteraçôes significativas em vários pontos simultaneamente, resultando que alunos de cursos cooperativos apresentam um desenvolvimento favorável com relaçáo à tomada de decisão e tempo de execução, à maturidade profissional e pessoal, ao senso crítico, capacidade de integrar teoria e prática, disciplina profissional e pessoal, iniciativa e espírito de liderança, espírito empreendedor, capacidade de comunicação, relacionamento humano, compromisso com a sociedade (MATAI; MATAI, 2005).

Silencia-se, no entanto, nos documentos analisados, aspectos referentes a formação dos professores para essa proposta. A ênfase do perfil discente no Currículo Cooperativo como um verdadeiro aprendente, ativo, autônomo na busca do conhecimento, capaz de construir suas aprendizagens de forma crítica, responsável e comprometida mediante a articulação de vivências acadêmicas com situaçôes reais e concretas, recontextualiza e reposiciona o papel do professor passando a exigir uma atuação docente diferenciada que demanda formação para a mudança. 
Contudo, apesar dessa lacuna, não se pode deixar de considerar que a proposta dos Cursos Cooperativos promove uma série de reflexóes e insights sobre como desenvolver e implantar um novo currículo para a formação do engenheiro.

$\mathrm{Na}$ sequência, passamos a analisar a segunda experiência alternativa que nos propusemos a analisar nesse artigo.

\section{CURRÍ́CULO POR PROJETOS E INOVAÇÃO NA EDUCAÇAO EMI ENGENHARIA}

As Diretrizes que orientam a organização curricular dos cursos de Engenharia no Brasil propóem como perfil do formando o engenheiro:

[...] com uma formação generalista, humanista, crítica e reflexiva, capacitado a absorver e desenvolver novas tecnologias, estimulando sua atuação crítica e criativa na identificação e resolução de problemas, considerando aspectos políticos, econômicos, sociais, ambientais e culturais com visão ética e humanista, em atenção às demandas da sociedade (BRASIL, 2002, p. 1).

No entanto, um panorama dos cursos de Engenharia revela que são escassas as organizaçóes curriculares que viabilizem o perfil proposto. A maioria dos currículos segue o paradigma tradicional, organizado por disciplinas de cunho científico e técnico, sem comunicação entre elas, afastadas dos contextos reais, com distanciamento entre teoria e prática, falta de formação em humanidades e escassas oportunidades de trabalho cooperativo.

Tem-se observado mudanças pontuais como a busca de novas abordagens metodológicas que favorecem a participação do aluno, trabalho em equipe, aprendizagem baseada em problemas, projetos colaborativos, estudos de casos, entre outros. $\mathrm{Ou}$, mudanças nos processos de avaliação, orientando-se de uma linha menos instrumental para uma orientação mais formativa. $\mathrm{Ou}$, ainda, a introdução de novas tecnologias. São experiências ricas que vem apontando importantes iniciativas, sem, contudo, terem conseguido ainda consolidar um novo perfil de formação.

Defendemos a ideia de que mudanças mais substanciais demandam novas arquiteturas curriculares, apoiadas em novos paradigmas curriculares capazes de promover alteraçáo em um conjunto de pontos ao invés de pontos isolados. Um paradigma curricular sustenta um campo conexo e interligado de aspectos, tais como visão de mundo, de sociedade, de homem, concepção de educação, papel das instituiçóes escolares, princípios epistemológicos, procedimentos metodológicos, perfil docente e discente, processos avaliativos, definiçãa de tempos e espaços, formaçãa de professores, entre outros. $\mathrm{O}$ conjunto desses itens colocados de modo interligado marca o tipo de educação e de 
formação que se deseja alcançar. Assim, para que uma inovação curricular se estruture e consolide, faz-se necessário alterar todos esses pontos na direção pretendida.

De posse desses direcionamentos, assumimos como desafio trazer para reflexão o potencial de uma organização curricular por projetos para novos cenários e novas perspectivas na educação em engenharia. Conduzimos essa reflexão a partir dos resultados de um estudo exploratório descritivo de abordagem qualitativa, compreendendo uma revisão bibliográfica sobre currículo e projetos e um estudo de campo em uma universidade pública brasileira, a UFPR Litoral, que vem adotando em todos os seus cursos uma organização curricular alternativa apoiada em uma proposta pedagógica fundamentada em projetos.

\subsection{A APRENDIZAGEM BASEADA EM PROJETOS}

Para Boutinet (2002), assiste-se a uma proliferação de expressóes e siglas para designar o recurso ao projeto no campo da educaçáo, sem que haja questionamento e clareza suficiente sobre os significados e usos que lhe são associados. Tal diversidade nos remete à necessidade de revisar a fundamentação e o significado de projeto enquanto intervenção metodológica a serviço do processo ensino-aprendizagem, para que possamos refletir sobre suas implicaçóes para uma organização curricular por projetos.

O trabalho com projetos não é novo na educação. Podemos situá-lo como uma prática pedagógica que obteve reconhecimento em diferentes momentos e movimentos educacionais. Sua origem nos reporta a John Dewey (1859-1952) e W.H. Kilpatrick (1871-1965).

Dewey faz uma denúncia ao estado de compartimentalização enfrentado na educação mediante a multiplicação de matérias, cada qual sobrecarregada de fragmentos desconexos, distanciados da vida real e que deveriam ser assimilados pela repetição. Propóe como alternativa as "ocupaçôes construtivas" que foram ganhando espaço e tornaram-se conhecidas como projetos. Kilpatrick deu prosseguimento às ideias de Dewey.

A busca dos fundamentos conceituais da metodologia de projetos nos leva a corrente filosófica do pragmatismo norte-americano e a teoria educacional progressivista. O pragmatismo concebe o mundo em constante transformaçáo. Enfatiza o conhecimento fundamentado na experiência e defende que o ser humano tem uma mente ativa e exploratória. O trabalho com projetos é um dos métodos favoritos dos pragmatistas. Dewey é um dos principais representantes dessa corrente filosófica.

A teoria educacional que recebeu forte influência do pensamento filosófico pragmático foi o progressivismo. Consequentemente, esta teoria educacional defende princípios, do ponto de vista epistemológico, com relação ao papel do aluno e do professor, à metodologia e ao currículo, 
muito próximos do posicionamento pragmático. William Kilpatrick está entre os educadores mais empenhados em aplicar a teoria educacional progressivista, daí o fato de ser ele considerado um dos precursores do método de projetos.

Segundo Hernandez (1998), os projetos em sua primeira versão caracterizavam-se pela ideia de partir de uma situação problemática, vincular a aprendizagem ao mundo exterior e oferecer uma alternativa à fragmentação das matérias.

A teoria educacional progressivista perdeu sua influência em meados da década de 1950, consequentemente os projetos que gozavam de prestígio nessa abordagem educacional também perderam sua influência. Hernández (1998) aponta ainda a racionalidade tecnológica que se configurou como ideologia dominante após a Segunda Guerra, como responsável pelo congelamento do uso de projetos.

Para esse autor, os projetos voltaram a despertar interesse a partir da metade dos anos 60 do século XX, ficando conhecidos de forma mais usual pelo nome de "trabalho por temas". As ideias de Piaget sobre o desenvolvimento da inteligência e sua relação com a aprendizagem de conceitos despertaram a indagação sobre que conceitos aprender e quais os critérios para selecioná-los. Bruner propôs a noção de conceitos-chave, que orientariam a organização de eixos conceituais, com o mesmo significado de grandes temas, ou temas aglutinadores.

Essa proposta leva à necessidade de reposicionar os conteúdos das disciplinas e repensar a maneira de abordá-los para que possam favorecer a relação entre conceitos e a transferência para outros contextos. Os projetos ou o trabalho por temas constituíram uma alternativa para abordar essa proposta na sala de aula. A proposta de Bruner desperta a noção de um currículo interdisciplinar, já que várias disciplinas têm conceitos-chave em comum.

Nos anos 90, a metodologia de projetos é revalorizada, pois coincide com as propostas curriculares atuais que buscam levar o aluno a pensar criticamente, a dar significado à informaçáo ao aplicá-la para planejar açôes, resolver problemas, criar novos materiais e ideias, envolvendo-se ativamente na aprendizagem. "Numa proposta relativamente recente, a utilização de projetos num processo pedagógico aparece com o sentido de proposição de uma prática pedagógica crítica, reflexiva e problematizadora" (BEHRENS, 2004 p.167).

Muitos dos princípios que se constituíram em fios condutores do trabalho com projetos conservam-se no paradigma educacional atual, como a visão de investigação de uma situação problemática (Dewey e Kilpatrick) e a organização de eixos temáticos (Bruner) têm sido proposiçóes defendidas na atualidade para superar a organizaçáo linear e disciplinar do conhecimento. No entanto, ao ser resgatado o trabalho com projetos adquire uma visão mais ampla, abordando o conhecimento de forma global, integrada e complexa. "A metodologia de projetos readquire pertinência quando abre como pressupostos: a visão de totalidade, a conexão das diversas áreas do conhecimento, o 
espírito crítico reflexivo, a busca da formaçáo para a cidadania e a recuperaçáo do posicionamento ético (BEHRENS, 2004, p. 165).

\subsection{CURRÍCULO POR PROJETOS COMO UM PARADIGMA CUR- RICULAR ALTERNATIVO}

Uma incursão à história do pensamento curricular nos permite situar o currículo por projetos num movimento cuja origem se situa na abordagem curricular progressivista de Dewey, evoluindo na atualidade para uma tendência curricular crítica, organizando-se sob as pressuposiçôes do código curricular integrado.

As teorias críticas surgem no início da década de setenta como uma reaçáo à concepção curricular tradicional, de ênfase tecnicista e burocrática, inspirada nos modelos de administração taylorista. A abordagem curricular crítica desloca a ênfase centrada nos aspectos técnicos de como organizar e elaborar o currículo limitado ao âmbito pedagógico, ampliando a análise para uma perspectiva sociológica em suas determinaçóes e conexóes com as estruturas econômicas e sociais mais amplas e com as relações de poder.

O currículo integrado tornou-se conhecido a partir de Basil Bersntein. No currículo integrado as fronteiras entre as áreas do conhecimento são menos nítidas. A organização do conhecimento se dá a partir de uma ideia central relacionadora, em vez de disciplinas isoladas. A abordagem curricular integrada não subestima o papel das disciplinas, mas propôe novas relaçôes para além da dominante organização disciplinar. Conforme Beane, na integração curricular "o conhecimento proveniente das disciplinas reposiciona-se no contexto do tema, questóes e nas atividades em causa" (BEANE, 2003, p. 106). Para Santomé (1998) uma das modalidades mais clássicas de integração curricular se dá por meio do trabalho com projetos.

São ainda pouco frequentes na literatura orientaçóes para o desenho de um currículo organizado por projetos. Moesby (2004) propôe os diferentes níveis de inserção dos projetos no currículo, desde um primeiro nível em que os projetos são usados como atividade dentro de cada disciplina, até o mais alto nível em que constituem um novo paradigma quando todo o currículo se estrutura por projetos. Nesse caso o projeto deixa de ser utilizado como uma metodologia de ensino, para ser usado como uma filosofia educacional.

Keller-Franco (2012) traz orientaçôes sugestivas para a elaboração de um currículo por projetos. A autora esclarece que os projetos organizam-se sob o guarda-chuva de um grande tema, normalmente semestral, que delimita e direciona o foco para o qual deve convergir a formação em suas dimensóes conceituais, procedimentais e atitudinais. 
Os resultados da pesquisa que realizamos, obtidos mediante a triangulaçáo das categorias analíticas obtidas com base no referencial teórico sobre projeto e currículo, bem como, as categorias empíricas obtidas mediante análise documental e entrevistas com alunos e professores da UFPR Litoral, desvelaram três grandes categorias viabilizadas em um currículo por projetos: a dimensão didático-pedagógica, a dimensão estrutural-organizacional e a dimensão político- cultural. Essas três grandes categorias desdobraram-se em subcategorias.

$\mathrm{Na}$ dimensão didático-pedagógica emergiram como subcategorias: a indissociabilidade entre ensino, pesquisa e extensão; relação de parceria entre professor e aluno; relação entre teoria e prática; interdisciplinaridade; conteúdos conceituais procedimentais e atitudinais; avaliação formativa; múltiplos domínios de espaços, tempos e tecnologias; referenciais epistemológicos que valorizam a construção do conhecimento a partir de problematizaçóes sociais concretas; abertura para a comunidade/sociedade como ambiente de problematização e aprendizagem e metodologia de ensino-aprendizagem fundamentada em projetos.

Uma inovação curricular por projetos não pode ser indiferente às complexas determinaçóes da prática pedagógica, é no espaço da sala de aula, no âmbito da dimensão didático-pedagógica que o currículo exerce sua maior parcela de ação ao pôr em prática os princípios e traços essenciais de um propósito educativo.

Por outro lado, em função da natureza sócio-formativa do currículo por projetos e do seu marco conceitual fundado nas teorias curriculares críticas e nos pressupostos do currículo integrado, este vai além dos aspectos didático-pedagógicos. Por incluir alterações no formato do currículo, superando a lógica disciplinar, contempla intervençôes no âmbito institucional e nos códigos de estruturação curricular, abarcando a categoria que denominamos de estrutural /organizacional, da qual emergem as seguintes subcategorias: organização curricular por temas ou grandes eixos e módulos; plano de visão; plano de ação.

Essa categoria apresentou-se como fundamental para uma inovação curricular por projetos. Para que um currículo por projetos possa ser implementado, é necessário todo um esforço e apoio institucional na organização do processo ensino-aprendizagem no sentido de superar o paradigma disciplinar tão dominante em nossos currículos. Será necessária também toda uma reflexão prévia, um plano de visão que ofereça uma percepção clara de onde se está aventurando e um plano de ação delineado que oriente as açóes dos envolvidos, gerando confiança na viabilização da proposta e tornando-a menos suscetível a resistências.

O currículo por projetos contempla ainda uma dimensão político cultural que configurou a terceira categoria. $\mathrm{O}$ currículo por projetos, enquanto teoria curricular crítica, altera e questiona o enfoque político social econômico hegemônico e dirige-se para abordagens emancipatórias do conhecimento e das relaçóes, visando a uma socialização crítica dos indivíduos. Isso implica considerar e rever valores culturais enraizados nos atores envolvidos no processo pedagógico, alterar 
as formas em que se processam as tomadas de decisão e investir em programas de formação para mudanças culturais e pessoais. Nesse sentido, a categoria político-cultural envolve subcategorias tais como: formação docente; perfil docente; perfil discente; planejamento e gestão participativa; avaliação e acompanhamento da inovação.

A forma como cada uma dessas categorias e subcategorias são viabilizadas em um Currículo por projetos podem ser encontradas com mais detalhes em Keller-Franco (2008). Os resultados encontrados na pesquisa trouxeram indicadores que nos permitem argumentar a favor do currículo por projetos como uma matriz de mudança em potencial para romper com o conservadorismo das práticas pedagógicas na educação superior. A partir de tais resultados argumenta-se sobre a viabilidade de uma organização curricular por projetos para delinear práticas inovadoras no ensino de engenharia desde consideradas as particularidades dessa área e dos contextos regionais, educacionais e institucionais.

\subsection{CURRÍCULO POR PROJETOS: INDICADORES DE INOVA- ÇÃOO PARA A ENGENHARIA}

Um dos desdobramentos significativos do currículo por projetos para uma inovação na educação em engenharia está em favorecer uma abordagem interdisciplinar do conhecimento. Os currículos tradicionais, organizados em disciplinas estanques, não dão conta da formação multidisciplinar exigida dos engenheiros para participar na solução dos problemas complexos da vida profissional. "O novo engenheiro deve ser capaz de propor soluções que sejam não apenas tecnicamente corretas, ele deve ter a ambição de considerar os problemas em sua totalidade, em sua inserção numa cadeia de causas e efeitos de múltiplas dimensôes" (Parecer CNE/CES n. ${ }^{\circ}$ 1.362). Para tal, o referido parecer sugere novas formas de estruturar os cursos. "Ao lado da tradicional estrutura de disciplinas organizadas através de grade curricular, abre-se a possibilidade da implantação de experiências inovadoras de organizaçáo curricular". O currículo por projetos, enquanto uma das modalidades mais clássicas de integração curricular (SANTOMÉ, 1998) constitui-se numa via por excelência para promoção da formação interdisciplinar.

Superação da dicotomia teoria-prática e entre ciências básicas e profissionalizantes é outro ponto que destacamos. Pesquisa realizada por Bringhenti (1993) com egressos da Escola politécnica da Universidade de São Paulo revela que o aluno vê muito pouco de engenharia no início da formação, as disciplinas são abordadas de forma muito teórica, os professores das matérias básicas não falam a linguagem dos engenheiros, o aluno recebe poucos esclarecimentos e não vê utilidade desses conteúdos na continuidade do curso. A superação da dicotomia formação básica e profissionalizante viabilizada mediante o currículo por projetos conforme resultados alcançados na pesquisa que realizamos, favorece ao aluno de engenharia conhecer e experimentar diferentes áreas de trabalho 
desde o início da formação, facilitando a descoberta de interesses e aptidóes e evitando a evasão tão comum nesses cursos. O contato imediato do aluno com a prática profissional contribui também para despertar para as exigências da ocupação e as possibilidades de satisfazê-la estimulando a atuação crítica e criativa na identificação e resolução de problemas conforme proposto nas Diretrizes Curriculares e tornando o aprendizado muito mais significativo. $\mathrm{O}$ trabalho com projetos tem como pressuposto a construçáo do conhecimento, valorizando uma prática pedagógica que parte da realidade e que retorna a essa mesma realidade mediante procedimentos que levam a observar, problematizar, buscar, selecionar e analisar informaçóes, elaborar propostas de intervenção, reconstruir e produzir conhecimento, em um movimento que integra teoria e prática, ciências básicas e profissionalizantes, aumentando a chances da obtenção de uma sólida formação acadêmica associada a uma larga experiência profissional.

Outro ponto relevante que se constatou no currículo por projetos, ausente nos currículos convencionais e que desenvolve atributos profissionais desejáveis aos engenheiros é a promoção simultânea de conhecimentos, habilidades e atitudes. Moraes (1999) defende que os profissionais da engenharia devem possuir conhecimentos de ciência, tecnologia, computação, administração, impactos ambientais e sociais da tecnologia, habilidades para a soluçáo de problemas, desenvolvimento de projetos, trabalho em equipe, comunicação, avaliação de pares e autoavaliação. Propóe ainda atitudes tais como ética, responsabilidade, iniciativa, flexibilidade, empreendedorismo e motivação para aprender com autonomia e ao longo da vida. O currículo por projetos atende à formaçáo proposta por Moraes. Ao pretender uma formação preparatória para compreensão do mundo no qual temos de viver e para a proposição de soluçóes criativas para os problemas que a realidade apresenta, o currículo por projetos, exige conteúdos mais amplos e complexos do que os restritos ao currículo acadêmico.

De acordo com Moura e Barbosa (2006, p. 218 - 219) "A proposta do ensino através de projetos representa uma forma importante de considerar todos os elementos da formação integral do ser humano. [...] Além disso, o processo favorece não apenas a aprendizagem de conceitos, mas ainda de procedimentos e atitudes em relação ao conhecimento e ao trabalho cooperativo".

Apresentam-se ainda como importantes desdobramentos do currículo por projetos favoráveis a uma nova abordagem no ensino de engenharia referenciais epistemológicos que valorizam a construção do conhecimento a partir de problematizaçóes sociais concretas, abertura para a comunidade/sociedade como ambiente de problematização e aprendizagem, bem como, múltiplos domínios dos tempos e espaços e tecnologias. A profissionalidade em engenharia hoje exige uma pró-atividade que permita participar nos processos produtivos considerando seus aspectos políticos, econômicos, sociais, ambientais e culturais com visão ética e humanística em atendimento às demandas da sociedade conforme o perfil apontado nas Diretrizes Curriculares do Conselho Nacional de Educação. No entanto a formação em engenharia tem ficado muito restrita a esfera 
da universidade. A aproximação com contextos profissionais autênticos costuma ser reservada para os estágios nos anos finais do curso e as aprendizagens adquiridas nesses espaços dificilmente retornam para problematizaçóes e reflexôes nos momentos convencionais das aulas. Além do mais a ampliação dos espaços de aprendizagem mediante os estágios costumam ficar muito restritas ao setor produtivo.

Em uma organização curricular por projetos ampliam-se consideravelmente os espaços incluindo-se também a comunidade, a realidade local e a sociedade mais ampla, levando o aluno a interagir com os contextos da realidade na busca de sólidas e sustentáveis soluçôes para as necessidades e problemas coletivos, favorecendo o exercício da profissão com compromisso social. Esse contato com a realidade social e profissional se dá desde o início do curso favorecida pela organização curricular por projetos, pois conforme Leite, Malpique e Santos (2001, p.57) "os projetos caracterizam-se como uma forma de articulação dos saberes escolares e dos saberes sociais".

Os aspectos levantados sobre a relevância de uma organização curricular por projetos para os cursos de Engenharia não se esgotam, outros mais poderiam ser destacados como um movimento na direção de mudanças substanciais para o ensino de engenharia, tais como avaliação formativa, um novo contrato na relação e papéis de professores e alunos.

Vale considerar que o trabalho com projetos adquire pertinência especial na área de engenharia já que esse é um campo profissional que se ocupa centralmente do processo de projetos. As diretrizes para os cursos de Engenharia recomendam o desenvolvimento de competências para trabalhar com projetos: [...] II) projetar e conduzir experimentos e interpretar resultados/ III) conceber, projetar e analisar sistemas, produtos e processos; IV) planejar, supervisionar, elaborar e coordenar projetos e serviços de engenharia; XII) avaliar a viabilidade econômica de projetos em engenharia [...]. (BRASIL, 2002, p. 1). Tais orientaçóes chamam atenção para o fato das graduaçóes oferecerem atividades que pouca aplicação tem fora das instituiçôes de ensino, enquanto na vida pós-escolar estarão de alguma forma envolvidos com projetos.

No Brasil são pouco comuns experiências com a abordagem de projetos enquanto metodologia ou paradigma curricular. Em âmbito internacional o trabalho com projetos está se firmando como uma importante inovação no campo da educação em engenharia. A obra organizada por Campos, Dirani, Manrique (2011) apresenta experiências concretas de vários países da Europa. Algumas dessas experiências já vêm sendo avaliadas e os resultados encontrados nas práticas com os diferentes níveis de utilização da abordagem de projetos revelam resultados semelhantes aos pontos inovadores que levantamos em nossa pesquisa sobre o currículo por projetos.

O currículo por projetos apresenta-se como uma possibilidade inovadora na educação superior e no ensino de engenharia, mas, não oculta desafios. Conforme nos lembra Castanho (2000, p.90) "[...] é relativamente fácil introduzir mudanças superficiais que não ameacem as estruturas existentes. Desafiar e mudar as estruturas profundas do ensino constituem o grande desafio". $\mathrm{Na}$ 
busca de caminhos possíveis, e, ao mesmo tempo comprometidos para alavancar e alterar estruturas enraizadas do ensino, não podem ser desconsiderados aspectos tais como: apoio institucional, clima organizacional, processo de planejamento participativo, formação de professores, flexibilidade do programa e dos atores para correçóes e construções emergentes no processo, comunicação aberta com os envolvidos como alunos, pais e comunidade, bem como, os fatores macro estruturais e seus determinantes sociopolíticos, econômicos e culturais, como por exemplo as regulaçôes externas que se avolumam no Ensino Superior, dentre tantos outros.

No entanto, tais dificuldades podem ser superadas pelo planejamento cuidadoso incluindo um plano de visão e de ação bem fundamentado e pelo valor adicional do paradigma curricular integrado sobre o paradigma tradicional para responder aos desafios da atualidade.

\section{CONSIDERAÇÕES FINAIS:}

Esta rápida análise dos Cursos Cooperativos e do Currículo por Projetos nos aponta para duas considerações finais.

A primeira diz respeito a identificarmos nestas propostas um currículo que tem condiçóes de responder às reflexôes que fizemos no início deste trabalho sobre a profissionalidade do engenheiro para a sociedade atual e sua respectiva formação. Afirmamos que a inserção do engenheiro em suas atividades profissionais continua exigindo especificidades, mas exige cada vez mais a colaboração de outras áreas do conhecimento de forma a lhes permitir compreender melhor os fenômenos e encontrar soluçóes mais eficazes para os problemas que se lhes apresentam. As propostas curriculares apresentadas promovem modificação em um conjunto de pontos, tais como: promoçáo de uma abordagem interdisciplinar do conhecimento, relação teoria prática desde o início do curso, alteração nos tempos e espaços de aprendizagem, metodologias ativas, avaliação formativa e construção do conhecimento a partir de realidades sociais e profissionais concretas.

A segunda, igualmente válida e instigante é podermos identificar que estas propostas curriculares só tiveram condições de se apresentar como uma alternativa para a formação de engenheiros porque tiveram a ousadia e a coragem de inovar na questáo curricular alterando não somente o desenho, mas também o paradigma curricular.

Não temos a intenção de apresentar respostas conclusivas, mas de deixar como contribuição a crença no novo, a coragem e o desejo de buscar novas alternativas curriculares. 


\section{REFERÊNCIAS}

BEANE, A. J. Integração curricular: a essência de uma escola democrática. Currículo sem fronteiras, v.3, n.2, p.91-110, jul./dez. 2003.

BEHRENS, M. A. A interconexão da metodologia de projetos com utilização de recursos informacionais num paradigma da complexidade. In: ENDIPE, 2004, Curitiba: Anais do ENDIPE, 2004, 2 v.

BOUTINET, J. P. Antropologia do projeto. Porto Alegre: Artmed, 2002.

BRASIL. Ministério da Educação. Diretrizes Curriculares Nacionais dos Cursos de Engenharia. PARECER No: CNE/CES 1362/2001, de 12 de dezembro de 2001. Relator: Carlos Alberto Serpa de Oliveira. Disponível em: <http://portal.mec.gov.br/cne/arquivos/pdf/CES1362.pdf >. Acesso em: 15 dez. 2016. BRASIL. CNE. Resolução CNE/CES 11/2002. Diário Oficial da Uniāo, Brasília, 9 de abril de 2002. Seção 1, p. 32.

BRINGHENTI, I. O ensino na Escola Politécnica da USP: fundamentos para o ensino de Engenharia. São Paulo: EPUSP, 1993.

CAMPOS, L. C.; DIRANI, E.A.T; MANRIQUE, A. L. (orgs). Educação em Engenharia: Novas Abordagens. São Paulo: Educ, 2011.

CASTANHO, M. E. Professores e inovações. In: CASTANHO \& CASTANHO (Orgs). O que há de novo na educaçáo superior: do projeto pedagógico à prática transformadora. Campinas: Papirus, 2000.

CONSELHO NACIONAL DE EDUCAÇÃO. Resolução CNE/CES 11/2002, aprovado em 11 de março de 2002. Institui as Diretrizes Curriculares Nacionais do Curso de Graduação em Engenharia. Diário Oficial da União, Brasília/DF, 9 de abril de 2002. Seção 1, p. 32.

FURTADO, Aline Fernanda. O desafio do ensino de engenharia frente aos problemas econômicos, energéticos e a sustentabilidade. Revista Triângulo, v.6, n.1, pp. 3-21, jan. a julho 2013.

HARGREAVES, A. O ensino na sociedade do conhecimento. Porto Alegre, Artmed, 2004.

HERNADEZ, F. Transgressáo e mudança na educação: os projetos de trabalho. Porto Alegre: Artmed, 1998.

KELLER-FRANCO, E. Currículo por projetos: inovaçáo do ensinar e aprender na educaçáo superior. Dissertação (mestrado em Educação: currículo). Pontifícia Universidade Católica de São Paulo, 2008.

Inovaçáo na educaçáo superior : o currículo por projetos. In : MASETTO, Marcos T. Inovação no ensino superior. São Paulo. Loyola, 2012.

LAUDARES, J. B.; RIBEIRO, S. Trabalho e Formação do Engenheiro. Revista Brasileira Estudos Pedagógicos. v. 81, n. 199, set. /dez. 2000. 
LEITE, E.; MALPIQUE, M.; SANTOS, M. R. Trabalho de projecto: aprender por projectos centrados em problemas. 4. ed. Porto: Afrontamento, 2001.

MASETTO, M. T. Memória de aula, Programa de Pós-Graduação em Educação Currículo da PUC/SP, maio/2005.

MASETTO, M. T.; PACHECO, C. O estágio e o ensino de engenharia. In: MASETTO, Marcos. Ensino de engenharia-técnicas para otimizaçáo das aulas. São Paulo, Avercamp, 2007.

MATAI, P.; MATAI, S. Ensino Cooperativo: estruturas quadrimestrais. COBENGE, 2001 (anais eletrônicos).

Ensino Cooperativo: o conhecimento das competências. Revista de Ensino de Engenharia, v.24, n.2, p.27-34, 2005.

MOESBY, E. Reflections on making a change towards projects oriented and problem- based learning. World Transactions on Engineering and Technology Education, Aalborg, Dinamarca, vol.3, n.2, 2004.

MORAES, M. C. O Perfil do engenheiro dos novos tempos e as novas pautas educacionais. IN: VON LINSINGEN, I. et al, (orgs). Formaçáo do engenheiro: desafios da atuação docente, tendências curriculares e questōes contemporâneas da educação tecnológica. Florianópolis: EDUFSC, 1999.

MOURA, D. G.; BARBOSA, E. F. Trabalhando com projetos: planejamento e gestão de projetos educacionais. Petrópolis: Vozes, 2006.

PEREIRA PINTO, D.; NASCIMENTO, J. L. (Orgs). Educaçáo em Engenharia. São Paulo: Mackenzie, 2002.

SACADURA, J. F. A formação dos engenheiros no limiar do terceiro milênio. In: LINSINGEN, I. V. Formaçáo do engenheiro. Florianópolis: Ed. UFSCAR, 1999.

SANTOMÉ, J. T. Globalização e interdisciplinaridade: o currículo integrado. Porto Alegre: Artes Médicas, 1998

UNIVERSIDADE DE SÃO PAULO. Escola Politécnica/Curso Cooperativo. Engenharia de Computação. Engenharia Química”. Manual do aluno, 2006. 